
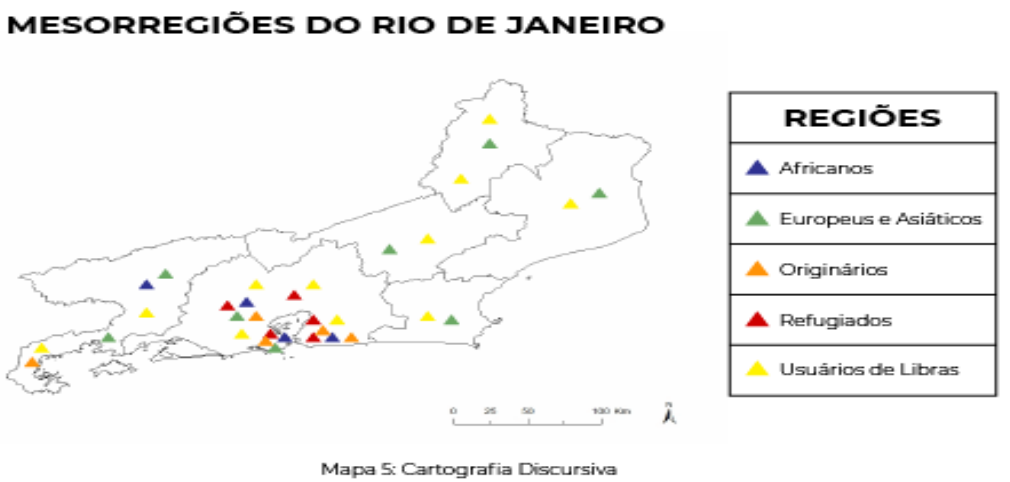

\title{
Plurilinguismo e cartografia discursiva do estado do Rio de Janeiro
}

Plurilingualism and discursive cartography of the state of Rio de Janeiro

\author{
Tania Conceição Clemente de Souza ${ }^{1}$ \\ ORCID ID: https://orcid.org/0000-0001-6782-7465 \\ Rodrigo Pereira da Silva Rosa ${ }^{2}$ \\ ORCID ID: https://orcid.org/0000-0001-9362-7651
}

Resumo: Como ponto de partida está o mapeamento das diferentes línguas faladas no Rio de Janeiro, com a proposta de uma cartografia discursiva. Enveredamos pela articulação de conceitos oferecidos pela Análise de Discurso de linha francesa e da escola europeia de Sociolinguística. Sendo o Rio de Janeiro polo que agrega povos de diferentes procedências, muitos são os entraves e problemas para acolher a todos. A principal barreira na solução para um bom acolhimento reside na diversidade de línguas que fluem com o trânsito de muitos imigrantes, de povos originários do Brasil e do fluxo constante de refugiados. A proposta de uma cartografia está, assim, na possibilidade de, ao mapear essas línguas, pensar no atravessamento do urbano pela sonoridade de tantas e diferentes línguas.

Palavras-chave: política linguística; plurilinguismo; cartografia discursiva

\begin{abstract}
The starting point is the mapping of the different languages spoken in Rio de Janeiro, with the proposal of a discursive cartography. We go through the articulation of concepts offered by French Discourse Analysis and the European school of Sociolinguistics. As Rio de Janeiro is a hub that aggregates people of different origins, there are many obstacles and problems to welcome everyone. The main barrier in the solution for a good welcoming resides in the diversity of languages that flow with the transit of many immigrants, native people from Brazil, and the constant flow of refugees. The proposal of a cartography is, thus, in the possibility, when mapping these languages, to think about the crossing of the urban by the sonority of so many different languages.
\end{abstract}

Keywords: language policy; multilingualism; discursive cartography

\footnotetext{
1 Doutora em Linguística pela Unicamp. Professora Associada do Departamento de Antropologia do Museu Nacional/UFRJ. Professora da Pós-graduação em Linguística da Faculdade de Letras/UFRJ. Coordenadora do LABEDIS/MN/UFRJ . E-mail: taniacclemente@gmail.com

2 Mestre em Linguística pela UFRJ. Doutorando em Linguística pela UFRJ. Membro do LABEDIS/MN/UFRJ. E-mail: rodrigopereirasr@gmail.com
} 


\section{Introdução}

Pensar acerca de Política Linguística ${ }^{3}$ no Brasil é, antes de tudo, entender que há aqui uma diversidade de línguas, e que se torna sempre necessário trazer a foco o tema do plurilinguismo ${ }^{4}$ - tão evidente no país -, contrário à política do monolinguismo, historicamente instituída.

Um país que tem sua formação marcada por contatos - com a presença de indígenas, portugueses e africanos e mais tarde com imigrantes de diversas procedências - ainda insiste na política do monolinguismo. Política essa cujo reconhecimento da língua portuguesa como a língua oficial e única (desde o século XVIII), ainda prevalece. O monolinguismo acarreta graves consequências para a comunicação e para a diversidade linguística, mas não impede a análise e reflexão de políticas linguísticas que reconheçam as mais variadas línguas e até mesmo as muitas variedades da própria língua tida como oficial.

Apesar de no Brasil serem faladas mais de 290 línguas, considerando-se as línguas indígenas e as línguas de imigração, juridicamente, através de decretos e leis, somente duas são as línguas reconhecidas oficialmente: o português e, bem recentemente, LIBRAS, instituída como meio oficial de comunicação ${ }^{5}$.

Com base nessas reflexões introdutórias, traçamos como meta geral, a partir de um levantamento exaustivo sobre as diferentes línguas que vêm sendo faladas no Rio de Janeiro, oferecer uma cartografia sobre essas línguas, levando em conta a presença não só de índios e imigrantes, mas também da presença de refugiados oriundos de vários continentes. A proposta de uma cartografia está, assim, na possibilidade de, ao mapear essas línguas, pensar no atravessamento do urbano pela sonoridade de tantas e diferentes línguas e presença do outro. Tal situação nos leva a esbarrar em algumas indagações: (i) Há previsão de uma política linguística que abarque esse universo de línguas? (ii) Uma vez instituída uma política de acolhimento, como se dá a hospitalidade dos sujeitos e suas línguas na cidade do Rio de Janeiro?

\footnotetext{
${ }^{3}$ Com base em Hamel (1988), recai sobre a noção de política linguística uma gama de sentidos variados, que cobrem desde a implantação de projeto de política linguística propriamente dito, até a observação de processos institucionais, menos evidentes, na forma, por exemplo, como são definidas línguas não oficiais - minoritárias ou minorizadas.

${ }^{4}$ As reflexões reunidas neste trabalho são resultados de dois projetos de pesquisa [Plurilinguismo e Política de línguas e Violência, fronteiras e refúgio: o jurídico e o político em torno da questão dos direitos humanos], que Souza desenvolve há alguns anos. A estes se vinculam trabalhos de conclusão de curso, tais como monografias, dissertações e teses. Espelham, também, as reflexões divulgadas por Souza em seminários no Brasil e no exterior, e em diferentes publicações, além de cursos de extensão/UFRJ.

${ }^{5}$ Decreto em: http://www.planalto.gov.br
} 
A resposta a essas questões configuram nossos objetivos e as bases teóricas de nosso trabalho estão fundadas na escola francesa de Análise de Discurso. Quanto às estratégias metodológicas de montagem da cartografia, estas se organizam com o enfoque das rotas migratórias dos diferentes povos que aqui chegam há algum tempo.

\section{Diretório de pombal: por uma disputa de território}

Uma política centrada na imposição de uma única língua, como é o caso do Brasil, tem sua origem ainda no século XVIII. Através do Diretório de Pombal, proibiu-se o uso da língua geral, de base Tupi, e se impôs como língua única o português. Foram razões de ordem jurídica, calcadas no Tratado de Madri, de 1750 (Cf: SOUZA, 2011), que levaram a Coroa Portuguesa à tal imposição. Por este tratado, seriam terras de Portugal por onde se falasse o português; e terras de Espanha por onde se falasse o castelhano.

A comparação do mapa abaixo serve para ilustrar a diferença de posse de terras de Portugal antes e depois do Tratado de Madri. Interessante a observar é que o acinzentamento das regiões, no âmbito do não verbal, significa "falar a língua portuguesa”. O idioma é assim usado para ratificar a expansão territorial das fronteiras entre Portugal e Espanha, principal mecanismo de poder na "guerra” pela colonização. E, provavelmente, tem-se aí a primeira cartografia linguística do português em nosso país.

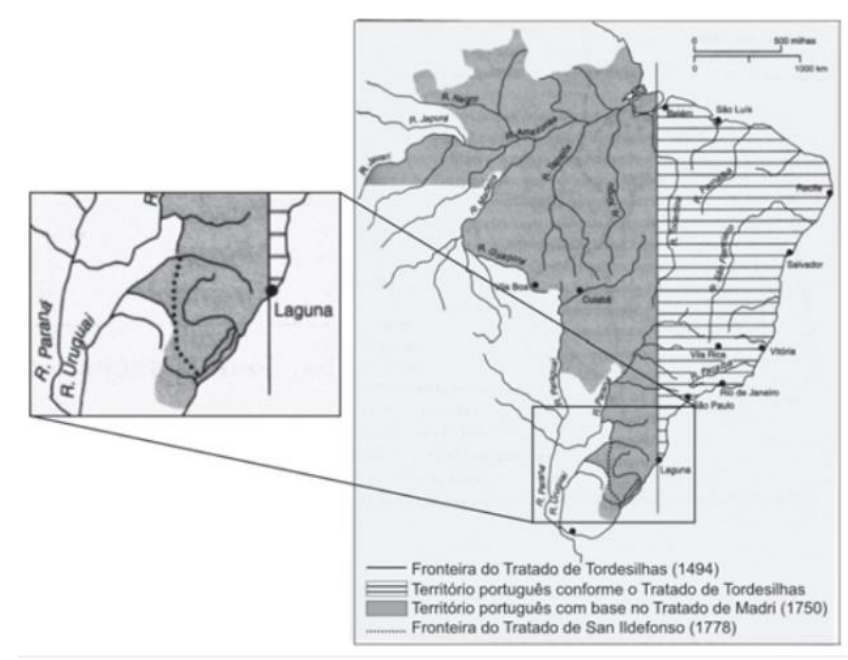

Figura 1: Representação do Tratado de Tordesilhas (1494) e do Tratado de Madri (1750). Fonte: FGV

A partir daí, são vários os movimentos, tanto de ordem linguística, quanto de ordem política, que vão disciplinando o modo de falar dos brasileiros, instituindo um 
imaginário em torno da língua. A interdição da língua dos imigrantes, por exemplo, foi uma constante durante o regime do Estado Novo.

Orlandi e Souza ${ }^{6}$ (1988, p. 27 e 28), ao analisarem a constituição da língua portuguesa falada no Brasil, observam que esse trabalho de disciplinização, além de persistir nas descrições linguísticas das línguas indígenas atuais, também se estende às considerações sobre a influência do Tupi do português, resumindo essa influência a uma lista de palavras que, em geral, denominam a topografia, a fauna e a flora. A partir desses dois fatos - a disciplinização do Tupi e do Português -, trabalham com o conceito de língua imaginária, o qual permite tanto explicitar as condições de produção da disciplinização, quanto dar conta da criação contínua "de artefatos (simulacros) que os analistas de linguagem têm produzido ao longo de sua história. (idem; 27; 28)."

Ou seja, a criação dos artefatos - diretórios, leis, decretos - e a criação dos instrumentos linguísticos - gramáticas, normas, coerções - trabalham em função do Estado garantindo-lhe a soberania e a individualização do cidadão e a exclusão disfarçada dos "maus cidadãos". Mais adiante, vamos nos deter na apresentação de uma cartografia instaurada com as várias rotas migratórias que vêm se dando desde o século XVIII em direção ao Rio de Janeiro. Com a atual configuração mundial dessas rotas, é cada vez crescente o número de línguas diferentes do português aqui faladas.

\section{Imigração e história}

O processo de imigração no estado do Rio de Janeiro se deu, primeiramente, com a vinda dos portugueses e africanos durante o período colonial do Brasil até o fim da escravidão (1500-1888). Devido a fatores externos e já conhecidos por nós (como a transferência da família real portuguesa para o Brasil e a necessidade de mão de obra - a cargo dos povos escravizados ${ }^{7}$ - para explorar e construir um local habitável), os portugueses foram sem dúvida o maior grupo de imigrantes no Rio de Janeiro (MENEZES, 2000) $)^{8}$, instalando-se em diversas regiões.

\footnotetext{
${ }^{6}$ Souza (2021) estende o conceito de língua fluida (também definido em Orlandi e Souza, idem) para negar a categorização de língua extinta, ou morta, com relação às línguas indígenas. As línguas migram, fluem para outros lugares e se silenciam. O que se tem são línguas silenciadas, mas que não se calam em várias instâncias.

${ }^{7}$ Desde o século XVI, chegam povos escravizados no Brasil pelas mãos de traficantes - metaforicamente cunhados de "senhores de escravos". Teria chegado ao Rio de Janeiro um total de 2 milhões de indivíduos entre 1758 e 1831. O principal porto de entrada é o Cais do Valongo, na região central do município do Rio de Janeiro.

${ }^{8}$ Toda a descrição das rotas migratórias está baseada, principalmente, em Menezes (2000).
} 
Os povos africanos tiveram sua imigração ocorrida de maneira forçada. Escravizados pelos portugueses, muitos chegaram ao estado vindos de Angola e eram destinados para as grandes lavouras e plantações, como as que existiam na região do Vale do Paraíba.

Do ponto de vista jurídico, a imigração de estrangeiros tem sua primeira oficialização em 1824, quando D. João VI se vê diante da necessidade de continuar a força produtora no país. As primeiras levas de imigrantes, excetuando-se os colonizadores e escravizados, começam a chegar no Brasil no século XIX ${ }^{9}$.

Ainda sob mandos oficiais, chegam os chineses durante o século XIX por ordem de D. João VI, abarcando um contingente de 2000 indivíduos.

Um dos movimentos políticos que contribui ao aumento de imigrantes no país é a instalação da política de embranquecimento. Num gesto de impedir a miscigenação, e manter a nata dos brasileiros de descendência nobre, levas dos povos de além-mar são muito bem-vindas.

Como processo de deslocamento maior e tentativa de embranquecimento - ou "desafricanização" da sociedade brasileira e civilização - foi aceita a entrada de cerca de 400 mil asiáticos (chineses, japoneses, árabes e judeus) para a atual região metropolitana do estado (onde hoje está a capital do estado, Rio de Janeiro) e também para a região da baixada fluminense (compreendendo os municípios de Nova Iguaçu, São João de Meriti, Mesquita, Duque de Caxias e Nilópolis). (LESSER, 2001, p. 90).

Também chegam já no final do século XIX e início do século XX, os imigrantes italianos, cujo povoamento foi predominantemente urbano, em busca de trabalho em comércios em geral. Ocupam o noroeste do estado, nas cidades de Varre-Sai, Itaperuna e em Porto Real.

Na primeira metade do século XX, deslocados para a cultura do café no Vale do Paraíba, chegam os finlandeses, cuja colônia - Pequena Finlândia - até hoje se localiza nessa mesma região, atualmente conhecida como Penedo. Nesta mesma época, vêm os ingleses. Estes passam a ter um grande papel na formação identitária fluminense, pois foram responsáveis pela produção das diversas linhas férreas e pela inserção da prática

\footnotetext{
9 “A "inauguração" da imigração europeia é atribuída à colônia suíça de Nova Friburgo, cuja instituição é sucedida pouco depois pela de Leopoldina, entre 1819 e 1820, mas o caso de Nova Friburgo introduziu uma inovação: é a primeira vez, de fato, que uma empresa colonial é contratada diretamente pelo governo português junto a um governo estrangeiro. Em 1818, uma série de medidas concretizou os acordos com a Suíça". (CROCI, 2011, p. 75)
} 
esportiva na vida da sociedade (como a criação do primeiro clube carioca, o Fluminense Football Club).

As rotas migratórias em direção ao Rio de Janeiro têm ainda duas direções. O movimento interno ao país com o deslocamento de um número considerável de indígenas para os grandes centros urbanos, aliados ao número cada vez maior de povos refugiados que aqui chegam em busca de acolhimento.

A história da colonização e dominação do país é pontuada pelas marcas dos inúmeros conflitos entre as populações indígenas e o Estado ${ }^{10}$. Esses embates, ao mesmo tempo que revelam posturas antagônicas entre os dois lados, significam os movimentos de resistência que vêm garantindo ao índio a preservação de sua identidade étnica. Hoje em dia esses movimentos vêm rompendo fronteiras, quando se configura uma busca por espaços que se projetam para além da demarcação oficial das terras indígenas. É o caso, por exemplo, do movimento de índios de diversas etnias que vêm, em diferentes rotas migratórias, se alojando em grandes centros urbanos, como no Rio de Janeiro, Vitória e São Paulo etc. Segundo dados do IBGE ${ }^{11}$, até 2010, havia um contingente aproximado de 16000 índios urbanos vivendo no Rio de Janeiro, pertencentes a diferentes etnias oriundas de várias regiões do Brasil.

A crise dos refugiados, segundo dados publicados pela Organização Internacional de Migração (OIM) e pelo Alto Comissariado das Nações Unidas para Refugiados (ACNUR), supera os dados de deslocamento desde a Segunda Guerra Mundial. Os motivos são as guerras causadas pelos movimentos fundamentalistas em alguns países. Até 2017, no Brasil, era estimado um total de 9 mil refugiados, a maioria de Sírios, Angolanos, Colombianos, República do Congo e Palestinos. Além de 80 mil haitianos, com visto de permanência (dados do Alto Comissariado das Nações Unidas para os Refugiados/ACNUR).

Para atender a essa demanda de constantes solicitações de refúgio a noção jurídica de refugiado vêm sendo redefinida. Muitos sentidos podemos atribuir ao sujeito que se desloca de seu país de origem para outro, e muitos motivos o levam a deslocar-se. Para tanto, é importante acentuarmos a diferença entre os termos "imigrante" e "refugiado", pois para além de questões jurídicas - que preveem direitos e privilégios - o uso de

\footnotetext{
${ }^{10}$ Estes conflitos perduram desde o século XVI até os dias atuais, como, recentemente, assistimos às manifestações de povos indígenas sobre a proposta do Governo Bolsonaro do "Marco Temporal", que propõe a redemarcação das terras dos povos originários.

${ }^{11}$ Dados com base nos resultados da amostra dos Censos de 1991 e 2010 do IBGE. A população indígena urbana atual deve ser bem maior no Rio de Janeiro, estimada em 30.000 indivíduos entre 5 a 65 anos.
} 
determinado termo também carrega consigo diferentes discursos e histórias, sendo estes importantes para observação.

Quem são os refugiados? "Ao nos depararmos com um total apagamento de referências étnicas quaisquer, todos parecem ser tratados como uma massa amorfa, sem identidade, lembramos de Bauman (2004, p. 108), ao citar Hannah Arendt, é "um saco de gatos a noção de refugiados". Em contraste, temos o vocábulo "acolhimento", que, dada a situação mundial dos que pedem refúgio, nos remete vez a Gadet e Pêcheux (1981): uma política de invasão, absorção e de anulação de diferenças." (Cf.: SOUZA, 2018a)

\section{Proposta de uma cartografia}

A oferta de uma cartografia ${ }^{12}$ de línguas faladas no estado fluminense vem ao encontro de atender a principal meta deste trabalho, que é a de projetar uma identidade linguística do Rio de Janeiro. São muitas as línguas faladas no estado fluminense, no entanto verificamos a ausência de um mapeamento dessas línguas. A presença dessas línguas no estado corresponde também a um número grande de falantes, considerandose, sobretudo, a afluência massiva de imigrantes que buscam no Rio de Janeiro uma acolhida. Atualmente, a grande maioria desses imigrantes é de refugiados. Mas como acolher a todos, se não vêm sendo pensadas políticas públicas que levem em conta tal situação? Não há planejamento para acolhidas na área da saúde, na educação e na cultura, apenas abrem-se as portas. Considerando que a principal barreira para os que aqui se instalam é a língua, um painel amplo das principais línguas aqui faladas poderá vir a contribuir para a eficácia do acolhimento. Por outro lado, como já apontamos anteriormente, a proposta de uma cartografia está, assim, na possibilidade de, ao mapear essas línguas, pensar no atravessamento do urbano pela sonoridade de tantas e diferentes línguas e vir a refletir sobre como se dá a hospitalidade dos sujeitos e suas línguas na cidade do Rio de Janeiro.

\section{Dados para uma cartografia discursiva}

Sobre as tentativas de cartografias linguísticas em território nacional, estas estão voltadas à variedade da língua portuguesa, que é falada de diferentes formas nas diversas

\footnotetext{
12 O termo "Cartografia" pode ser aplicado a qualquer operação de base científica que tem por objetivo representar resultados obtidos através de mapas de cunho geográficos. Por extensão e pela concepção ampla deste termo, também pode ser aplicado na área linguística. Desde muito tempo, os pesquisadores da linguagem têm elaborado representações em mapas sobre a diversidade linguística no país. (ROSA, 2020).
} 
regiões geográficas do país. Não temos até o presente momento um mapeamento linguístico que dê conta da diversidade de línguas faladas em território nacional, a não ser o Inventário Nacional da Diversidade Linguística (2010), que funciona também como um objeto cartográfico, pois nele pode-se verificar geograficamente onde estão localizadas as línguas e quais línguas são faladas no território brasileiro. Porém, o inventário da diversidade linguística sofreu poucas alterações desde sua criação e, recentemente, conforme divulgado pelo site $\mathrm{G} 1^{13}$, o atual governo criou uma comissão para avaliar a inclusão de línguas no INDL, mas tal medida ainda não está em desenvolvimento.

O estado do Rio de Janeiro, pelos fatores já aqui citados, ainda carece de um mapeamento linguístico da diversidade de línguas que aqui são faladas. A saída, pensada por nós, se dá através de uma cartografia de cunho discursiva, para que possa servir de instrumento de estudos futuros, uma vez que é notória a diversidade linguística aqui presente. Além de ser um estado cuja formação se deu através do contato, o Rio de Janeiro também foi por muito tempo o estado que abrigou a capital do país (1763-1960), fator que também influencia para tal diversidade.

Com fins à sistematização, a nossa concepção de uma cartografia discursiva toma como estratégia de base a organização de tabelas, feitas a partir do levantamento histórico de povos que têm afluência ao estado do Rio de Janeiro (cf: seção Imigração e história, acima). Organizamos 5 tabelas abaixo seguindo alguns critérios. Na primeira tabela [1], partimos dos dados oferecidos pelo PARES/Cáritas RJ ${ }^{14}$ em 2017. Pesquisamos em diferentes fontes, mas, sobretudo no site do IPOL (http://ipol.org.br/), as línguas faladas nos locais de origem dos refugiados tendo como destino o estado do Rio de Janeiro. Temos um total de 53 locais de procedência, o que corresponde a um total de 165 línguas oficiais nos países de origem, além de um total aproximado de mais de 200 línguas não oficializadas, totalizando mais de 300 línguas e variedades dialetais. Desse total de procedências, nos concentramos em ilustrar apenas os 14 locais de procedência com mais afluência ao Rio de Janeiro.

\footnotetext{
${ }^{13}$ Conferir: https://g1.globo.com/educacao/noticia/2019/07/25/ <Acesso em 04/12/2019 as 16h30>

${ }^{14}$ Programa de Atendimento a Refugiados e Solicitantes de Refúgio, com sede na cidade do Rio de Janeiro. A tabela que nos foi cedida não consta do site da Cáritas RJ. Por deferência ao nosso projeto, esta nos foi enviada por mensagem via e-mail.
} 


\begin{tabular}{|c|c|c|}
\hline PAÍS & $\begin{array}{c}\text { LÍNGUA } \\
\text { OFICIAL }\end{array}$ & DEMAIS LÍNGUAS \\
\hline Congo & Francês & $\begin{array}{c}\text { lingala, quicongo, kituba, suaíli e tshiluba [status } \\
\text { de línguas nacionais] }\end{array}$ \\
\hline Colômbia & Espanhol & kpellé, bassa, vai e grebo \\
\hline Libéria & Inglês & francês, curdo e armênio \\
\hline Síria & árabe & punjabi, urdu, $\underline{\text { saraiki, pastó, sindi, balúchi }}$ \\
\hline Líbano & árabe & padrão, siríaca \\
\hline Pakistão & inglês & aramaico, turcomeno, armenio, árabe moderno \\
\hline Iraque & $\underline{\text { árabe e curdo }}$ & Krio \\
\hline Sérvia & língua sérvia & \\
\hline Serra Leoa & inglês & Árabe \\
\hline Cuba & espanhol & \\
\hline Palestina & árabe & \\
\hline Somália & somali & \\
\hline Afeganistão & pachto e dari & \\
\hline
\end{tabular}

Tabela 1: Refugiados e línguas no Rio de Janeiro

Com as informações oferecidas pelo PARES/Cáritas RJ, é possível chegar a um bom arrazoado de línguas que podem estar sendo faladas no Estado brasileiro, como um todo [tabela 1]. Refugiados chegam a todo o momento e em qualquer lugar do país. Dessa presença, temos o contato entre refugiados e brasileiros, sendo flagrante o modo de falar o português, que com certeza pode ter como herança novos vocábulos, como tem acontecido com a relação do português com as demais línguas de imigração. A tabela [2] a seguir traz o arrolamento das línguas dos imigrantes ${ }^{15}$.

\begin{tabular}{|c|c|}
\hline PAÍS & LÍNGUA OFICIAL \\
\hline Alemanha & alemão \\
\hline Suíça & alemão. francês, italiano e romanche \\
\hline China & mandarim \\
\hline Síria & árabe \\
\hline Líbano & árabe \\
\hline Japão & japonês \\
\hline Itália & italiano \\
\hline Finlândia & finlândes e sueco \\
\hline
\end{tabular}

\footnotetext{
15 Tomamos como base para a realização desta tabela [2] o histórico das rotas de imigrantes descrito na seção Imigração e história deste artigo.
} 


\begin{tabular}{|c|c|}
\hline Inglaterra & inglês e córnico \\
\hline Espanha & espanhol \\
\hline Polônia & polonês \\
\hline Rússia & russo \\
\hline Ucrânia & ucraniano \\
\hline
\end{tabular}

Tabela [2]: Imigrantes e Línguas no Rio de Janeiro

Refletir sobre a tabela [2] com línguas dos imigrantes, nos leva a retomar o conceito de línguas minoritárias e línguas minorizadas: aquelas pensadas em Hamel (1988, p. 43) a partir das "trocas linguísticas entre si, o surgimento de conflitos, os processos de deslocamento, resistência e ressurgimento de línguas minoritárias"; e estas definidas "ainda que dividindo o mesmo território com outras línguas, não gozam de privilégios em relação ao uso, sendo assim excluídas social e politicamente.” (ARACIL, 1983, apud PONSO, 2017; p. 193). Em questão está aí o tratamento de ordem políticoideológica que recai sobre essas línguas de imigrantes. De imediato, temos um tratamento numérico em vários documentos oficiais sobre estas línguas - inclui-se entre estes o Censo do IBGE. São línguas minoritárias porque são faladas por um contingente menor de falantes, mas são estes considerados como agentes de nossa história e citados em documentos e em textos de cunho científico e acadêmico. Sua força de trabalho é reconhecida como meritória na construção e manutenção do país. As mesmas considerações não podem ser estendidas aos povos indígenas, de línguas minorizadas - e muitas vezes faladas por um grande número de falantes -, nem tampouco aos povos escravizados.

Um gesto importante foi dado pelo IBGE, quando em 2010, lança o resultado do censo com as populações indígenas. Pela primeira vez os indivíduos dessas populações são mapeados por faixa etária, vivência em contexto urbano ou aldeados e pela classificação como falantes monolíngues e bilíngues. Mas sem referência ao pertencimento étnico - quem são esses povos? - e sem referência ao idioma - quais e quantas línguas falam os povos originários? Sabemos por dados oficiais (IBGE) que vivem no Rio de Janeiro, em contexto urbano, 16.000 índios de etnias as mais diversas e 450 índios Guarani Mbya originários do Rio de Janeiro e alocados nas aldeias Araponga, Guarani Araponga, Guarani de Bracui, Parati-Mirim e Tekoha Javi (Rio Pequeno). E seu papel nos compêndios de história? Falavam Tupi - como se todos os indígenas fossem da 
etnia Tupi e falassem a mesma língua ${ }^{16}$, adoravam Jaci (a lua) e Guaraci (o sol), moravam em ocas, dormiam em redes, comiam caça e raízes, andavam nus e eram pagãos. Num tom irônico, reproduzimos em resumo tudo que historicamente tem sido dito sobre nossos povos originários. O uso dos verbos no tempo passado não é escolha nossa, é registro da forma como os livros de história falam dos indígenas. Povos sem história, sem lei, sem rei, sem fé. Povos, negativamente, marcados pela falta. Não temos como fazer uma tabela: faltam dados nominais das rotas migratórias para os grandes centros ${ }^{17}$.

Quanto às línguas de origem africana, podemos recuperá-las por trabalhos de pesquisadores no campo da Linguística e no campo da Arqueologia. No Rio de Janeiro, vamos retomar parte da história do Cais do Valongo (sítio arqueológico) e cruzar com dados em Petter (2011) e Castro (1983), recuperando a afluência dos povos africanos ao nosso país. Uma ressalva, no entanto, se faz necessária quando Petter afirma que as línguas de matriz africana não se consolidaram em solo brasileiro como línguas plenas. Mas nos deixaram herança, o que discutiremos mais adiante.

\begin{tabular}{|c|c|}
\hline \multicolumn{2}{|c|}{ Tronco Nigero-congolês } \\
\hline Famílias & Grupos \\
\hline $\begin{array}{l}\text { - Atlântica: fula (fulfulde), uolofe, } \\
\text { manjaco, balanta; } \\
\text { - } \text { Mande [sobretudo o mandiga]: } \\
\text { bambara, maninca, diúla; } \\
\text { - } \quad \text { Gur: subfamília gurúnsi; } \\
\text { - Cuá [subgrupo gbe]: eve, fon, gen, aja } \\
\text { [designadas pelos termos jeje no } \\
\text { Brasil]; } \\
\text { - } \quad \text { Ijoide: ijó; } \\
\text { - } \quad \text { Bênue-congolosa }\end{array}$ & $\begin{array}{l}\text { - } \quad \text { Defoide: falares iorubás [designados no } \\
\text { Brasil pelo termo nagô-queto]; } \\
\text { - } \quad \text { Edoide: edo; } \\
\text { - } \quad \text { Nupoide: nupe (tapa); } \\
\text { - } \quad \text { Iboide: ibo; } \\
\text { - } \quad \text { Cross-River: efique, ibíbio }\end{array}$ \\
\hline
\end{tabular}

Tabela [3]: Povos africanos e línguas da área oeste-africana no Brasil

\footnotetext{
${ }^{16}$ O Censo 2010/IBGE revelou que hoje 274 línguas indígenas são faladas no país por 37,4\% dos índios com mais de cinco anos de idade. Do total, seis mil deles falam mais de duas línguas. A fluência em pelo menos uma delas foi verificada em 57,3\% dos índios que vivem em terras indígenas brasileiras. Maiores informações: www.funai.gov.br <Acesso em 07/01/2020 às 16:29>.

${ }^{17}$ Por conhecimento pessoal, sabemos que índios de diversas etnias residem no Rio de Janeiro, mas esse tipo de dado não é suficiente para mapear a etnia/língua de todos os indígenas aqui alocados.
} 


\begin{tabular}{|c|c|}
\hline Tronco afro-asiático & Tronco Nilo-saariano \\
\hline - Família Chádica: hauçá & - Família Saariana: canúri \\
\hline $\begin{array}{ll}\text { - } & \text { Congo (quicongo): quissolong } \\
\text { pelos bacongos, numa zona co } \\
\text { (fiote), quiombe [faladas em C } \\
\text { - } \quad \text { Quimbundo [falada pelos aml } \\
\text { antigo reino de Ndongo], quiss } \\
\text { - } \quad \text { Iaca-holo: íaca, imbangala, chi } \\
\text { - } \quad \text { Chôcue: uchôcue, ochingangue } \\
\text { - } \quad \text { Luba: chibluba-cassai (lulua); } \\
\text { - } \quad \text { Lunda: chilunda, urunda; } \\
\text { - } \quad \text { Macua: omacua; } \\
\text { - } \quad \text { Umbundo [falada pelos ovimb } \\
\text { - } \quad \text { Cunianiama, indonga: ochiacuar } \\
\text { - } \quad \text { Herero: ochiherero }\end{array}$ & $\begin{array}{l}\text { ngala), quizombo, quissundi [falada } \\
\text { go reino do Congo], quivíli, iuoio } \\
\text {;; } \\
\text { itral de Angola, correspondendo ao } \\
\text { Benguela, em Angola]: umbundo, }\end{array}$ \\
\hline
\end{tabular}

Tabela [4]: Povos africanos e línguas da área austral no Brasil

As tabelas [3] e [4] acima reproduzem a classificação das línguas transplantadas para o Brasil, segundo Petter (2011, p. 260-261). O que aí se observa é a grande diversidade de línguas que eram faladas pelos povos que aqui chegaram em oposição ao fato de elas perderem a sua fluidez como línguas plenas. O Cais do Valongo, no Rio de Janeiro, foi um dos portos mais importante de ancoragem dos navios negreiros e do comércio dos povos aprisionados.

Do tráfico de quase 5,8 milhões de aprisionados por Portugal, cerca de 95\% deles chegam ao Brasil. Com esses dados, Portugal ocupa o primeiro lugar no ranking dos países que praticaram o tráfico de povos africanos nos séculos XVIII e XIX. O Rio de Janeiro se constitui, então, como principal centro distribuidor de escravos para outros estados. Recentemente descoberto, o Cais do Valongo (sítio arqueológico no centro da cidade do Rio de Janeiro) representou a reunião de toda complexidade que envolvia o comércio de escravos, sobretudo no século XVIII. Ali chegaram povos vindos do Congo, Angola e Moçambique ${ }^{18}$.

Cruzando as informações históricas sobre as regiões de onde veio a leva de povos para o Rio de Janeiro com as tabelas oferecidas por Petter (2011), chegamos à tabela [5] abaixo com a distribuição dos povos e das línguas de matriz africana que fazem parte do português brasileiro e da variedade dialetal fluminense:

\footnotetext{
${ }^{18} \mathrm{Cf}$ : https://www.bbc.com/portuguese/brasil-45092235 <Acesso em 30/12/2019, às 14:42>

e https://xn--histria o0a.ufrj.br/images/documentos/dossie_valongo.pdf <Acesso em 30/12/2019, às 15:20>
} 


\begin{tabular}{|c|l|}
\hline Região & \multicolumn{1}{|c|}{ Línguas africanas (século XVII e século XVIII) } \\
\hline Angola & $\begin{array}{l}\text { umbundo }(\text { Umbundu), quimbundo (Kimbundu), quissama, quindongo, } \\
\text { olunianeca, chilunda, urunda, }\end{array}$ \\
\hline Congo & $\begin{array}{l}\text { quissolongo, quissicongo (quissangala), quizombo, quissundi, quivíli, } \\
\text { iuoio (fiote), quiombe, íaca, imbangala, chinji, ochiacuaniama, cuambi }\end{array}$ \\
\hline Moçambique & omacua, línguas homogêneas tipologicamente \\
\hline
\end{tabular}

Tabela [5]: Povos Africanos e línguas no Rio de Janeiro

A questão em torno das línguas de matriz africana, tendo como fato de não permanecerem como línguas plenas, não diminui a sua importância na constituição do português brasileiro. A vivência dessas línguas perpassa a memória de diversos falares distribuídos pelo Brasil em todo seu território.

A partir de Castro (1983), é possível recuperar o quanto de herança essas línguas nos deixaram. Com base na observação de "duas situações socioculturais distintas e da escolha sistemática entre a mudança ou não de variedade linguística”.

Dessas práticas socioculturais, surgem vários repertórios linguísticos dos quais nascem variedades de línguas, como é o caso da língua-de-santo, fluente nas religiões de matriz africana. Ainda como herança dessas línguas, podemos registrar aqui o pajubá ou bajubá, língua falada pelos LGBTs, em Moura (2018, p. 105), assim definido:

Bajubá - s.m. Baseado nas línguas africanas empregadas pelo candomblé,é a linguagem praticada pelos travestis e posteriormente estendida a todo universo gay. O bajubá falado emprega uma mistura lexical (do próprio bajubá, do português e, em menor grau, do tupi) sobre a base gramatical e fonológica da língua portuguesa. [var.: pajubá].

Os dados arrolados até aqui nos permitiram projetar tabelas que ilustram a diversidade linguística que atravessa a memória discursiva do português do Brasil e que sedimenta também o falar fluminense. Nesse universo, não se pode excluir os usuários ${ }^{19}$ de LIBRAS, contabilizados, de acordo com o Censo 2010 do IBGE, em quase 10 milhões de brasileiros com deficiência auditiva e de não deixar ressaltar, mais uma vez, a importância política de LIBRAS ao ser promovida como instrumento de comunicação legal no país, ao lado da língua portuguesa, idioma oficial do Brasil.

\footnotetext{
${ }^{19}$ No questionário do Censo, não há perguntas sobre falar ou não LIBRAS, por isso no montante de 10 milhões, incluem-se falantes e usuários de LIBRAS. Agradecemos esta observação à Angela Baalbaki.
} 


\section{Uma cartografia discursiva}

O termo 'cartografia discursiva', cunhado em Rosa (2020, p. 82), "toma como base na sua definição aspectos de ordem político-social, quando estes dão lugar a um desenho da diversidade de línguas - em sua forma plena ou não - faladas no estado fluminense." A reunião dessas línguas não se dá por um fato fortuito, ao contrário: cada povo que aqui chega com sua matriz linguística traz consigo movimentos na história - do seu lugar de origem ao novo território.

Uma cartografia discursiva não pode ser resultado, apenas, de um levantamento estatístico. Ela se constrói investindo na busca por fatos históricos: por que aqui chegam os imigrantes? por que aqui chegam os povos africanos? por que aqui chegam os povos originários? e, por fim, por que os refugiados buscam o nosso território como lugar de acolhimento? São essas questões que tecem as filiações históricas materializadas numa cartografia da ordem do discurso. Filiações definidas em Souza (2001) como "um trabalho intrínseco à intertextualidade e na textualização do político.”

Todas essas questões sustentaram nosso ponto de partida e procuramos respondêlas dentro do possível ao longo do trabalho. E por esse trajeto podemos verificar a eficácia do conceito de 'acontecimento discursivo', formulado em Pêcheux (1990, p. 19): “o acontecimento [...] em seu contexto de atualidade e no espaço de memória que ele convoca”. Ou seja, um encontro de uma memória com uma atualidade.

A memória das rotas migratórias esbarra na atualidade do acontecimento. Os negros aprisionados foram buscados em Congo e Angola; os refugiados que vêm do continente africano partem desses mesmos "portos": $25 \%$ dos refugiados vêm da República Democrática do Congo; de Angola vêm 13\%, entre os dez países de onde mais se têm procedências de refugiados ${ }^{20}$.

Com a falência do regime de escravatura, outros povos são "aprisionados" sob a alcunha jurídica de imigrantes. Desde o século XVI (considerando-se a imigração involuntária dos africanos), aqui chegam, oficialmente, por vontade própria: suíços, chineses, japoneses, árabes e judeus. Ao final do século XIX e início do século XX, chegam os italianos. Na primeira metade do século XX, chegam os finlandeses; nessa mesma época vêm os ingleses.

\footnotetext{
${ }^{20}$ Com a crise na Venezuela, esses dados sofrem mudanças. Têm sido registradas grandes levas de Venezuelanos que chegam ao país, mas como legalmente não podem ser classificados como refugiados, sua presença não é mencionada em censos e documentos oficiais. Mas constam dos dados fornecidos pela Cáritas: em 2019, agrupando apenas os 7 primeiros países, chegou um total de 2133 solicitantes de asilo, dentre os quais $1082(52 \%)$ são de Venezuelanos.
} 
A afluência de indígenas ao Rio de Janeiro abre uma nova rota na história e, por outras razões históricas, acaba por atualizar o movimento de deslocamento do índio urbano:

(...) que se movimentam tanto nos "complexos" (Rocinha, Alemão, Maré...) quanto nas reservas ambientais ou casarões históricos (como no prédio em ruínas do ex- Museu do Índio). São esses espaços pontos de fuga onde o índio se recolhe, encolhe, se mostra. Locais que acabam por re-significar toda uma memória discursiva transversa sobre as antigas rotas migratórias tribais. (SOUZA e ARAÚJO, 2010, s/p).

Enfim, a nossa cartografia discursiva historiciza todos esses movimentos da história, movimentos esses ilustrados nos mapas do estado do Rio de Janeiro dividido em mesorregiões. Confira-se, a seguir, a distribuição das rotas migratórias.
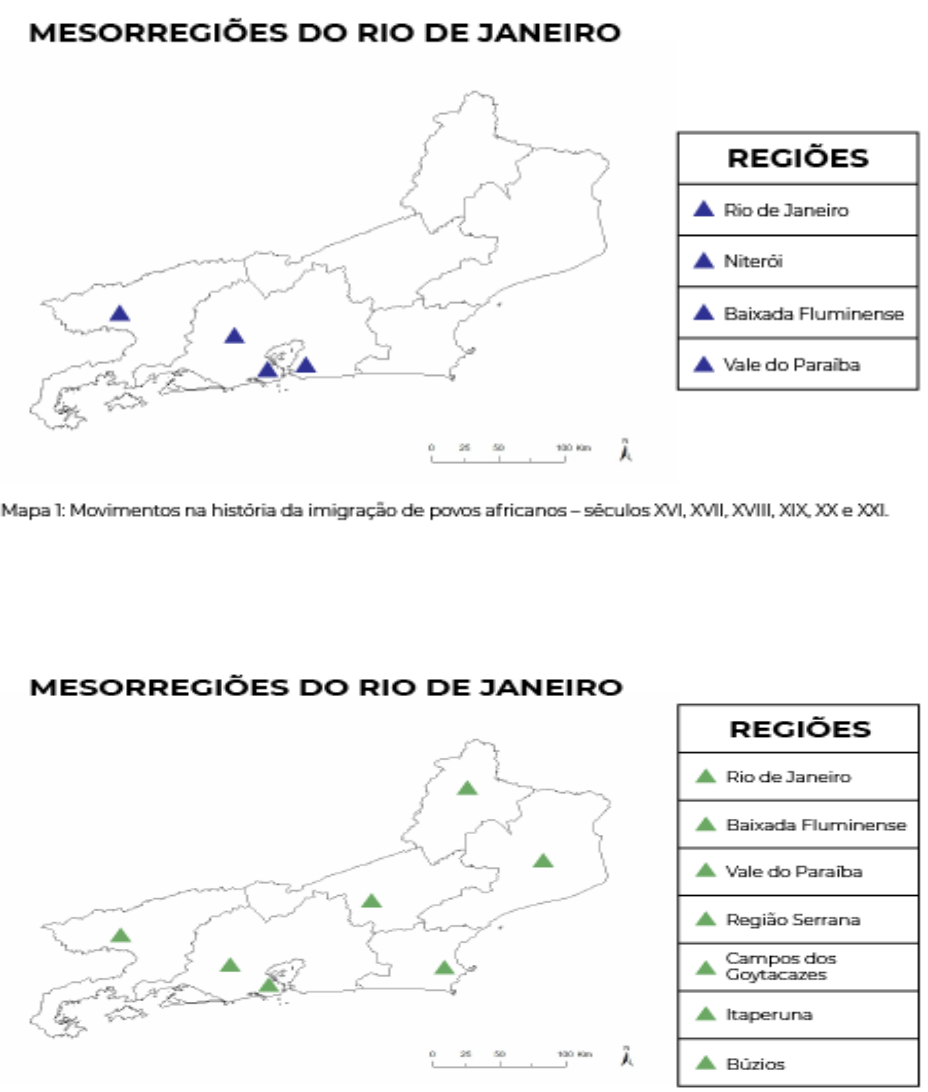

Mapa 2: Movimentos na história da imigraçẫo de ponos europeus e asiáticos - sêculos XXX, XX e XXXI. 


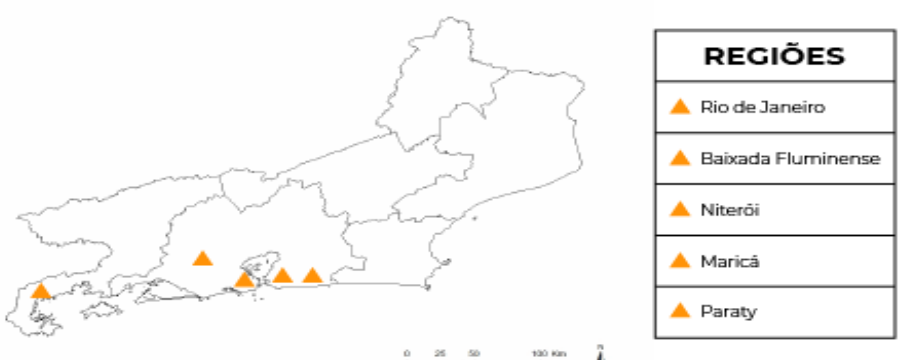

Mapa 3: Movimentos na história da imigraçâo de povos originários - séculos XIX XX e XXI.
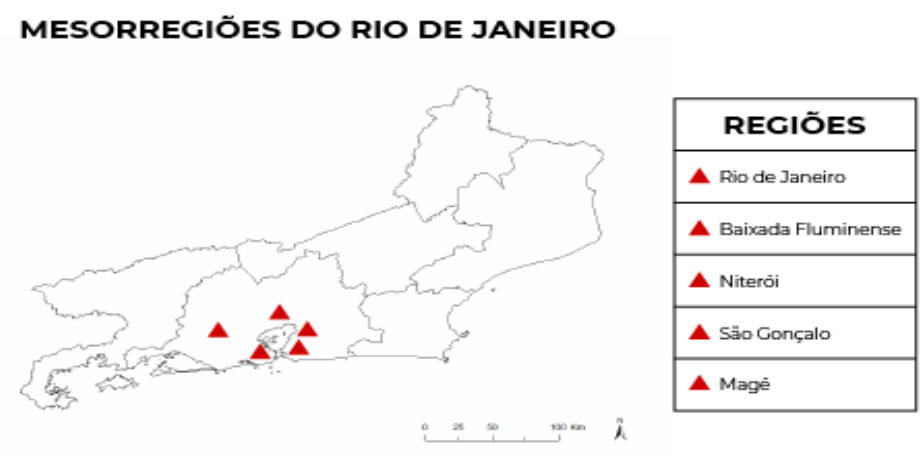

Mapa 4: Movimentos na histốria da imigraçäo dos refugiados - sếculos XX eXXI.
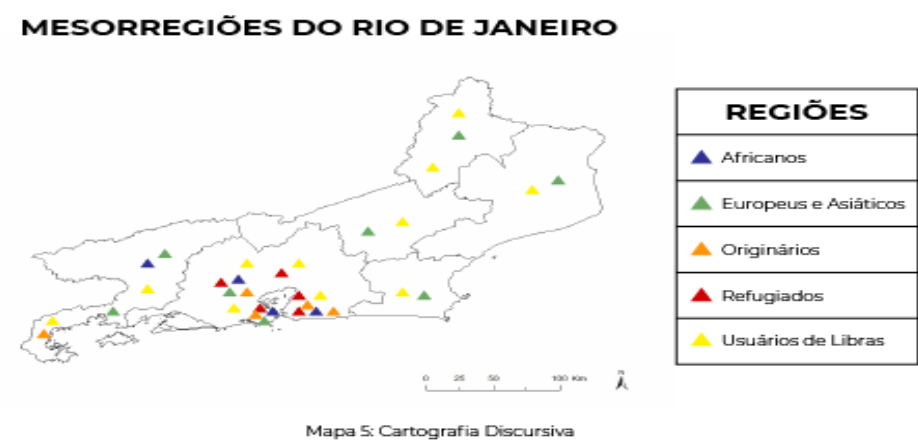

Para a produção desta cartografia, utilizamos o mapa de composição feito pelo IBGE. Nesta composição, a divisão geográfica regional do país se dá através das mesorregiões e microrregiões ${ }^{21}$. As mesorregiões são regiões que congregam diversos municípios de uma área geográfica de um estado brasileiro com similaridades econômicas e sociais. Como visto nos mapas acima, o estado do Rio de Janeiro é composto, de acordo com a divisão das mesorregiões, em 6 regiões geográficas, sendo elas: (i) Noroeste Fluminense, (ii) Norte Fluminense, (iii) Centro Fluminense, (iv) Baixadas Litorâneas, (v) Sul Fluminense e (vi) Metropolitana do Rio de Janeiro.

\footnotetext{
${ }^{21}$ Esta divisão se dá pela referência à rede urbana. www.ibge.gov.br <Acesso em 10/01/2020, às 11:50>
} 
Em nosso mapa discursivo, observamos a presença de todos os povos já citados até aqui distribuídos pelas diversas regiões. Há também a inserção dos falantes e usuários de LIBRAS. Todos esses povos se estabelecem ao longo de todo o território fluminense, mantendo seus costumes, sua cultura e tendo a língua portuguesa como instrumento de comunicação comum a todos.

Nossa intenção foi colocar em foco o alcance político que envolve a confecção de cartografias. Desde o mundo antigo, a oferta de cartografias se define por uma postura político-ideológica, ora para se projetar - muitas vezes de forma multidimensionada - o desenho de territórios conquistados, ora para se alardear, no caso do nosso território, práticas criminosas, como a denúncia do desmatamento, resultante da exploração do paubrasil, já no século XVI.

$\mathrm{Na}$ contemporaneidade, a oferta de cartografias e atlas linguísticos são feitos a partir do registro de dados de uso do léxico, ou das variações fono-dialetais. Essa proposta pressupõe um levantamento quantitativo visando uma amostragem de variação de determinados falares, ou dialetos.

A diferença entre uma cartografia discursiva e uma cartografia linguística, ou um atlas linguístico, reside no objetivo de não se buscar ilustrar uma visão em tempo aparente das mudanças atestadas em determinado dialeto, deslocando as mudanças em tempo real. Deste processo, resulta a discriminação entre as variantes de prestígio e as de uso vulgar. As diferenças de qualquer ordem têm um curso na história, e este curso é movido por fatos e razões de ordem político-ideológica. Movimentos de escravização, movimentos de embranquecimento, movimentos de genocídios e de atos terroristas, enfim, movimentos de espoliação humana fazem de nossa sociedade, uma "sociedade líquida". Enfim, uma cartografia de línguas que reflita todos esses movimentos não só recobre a rota das migrações, como acaba por deflagrar a materialidade discursiva da fluidez das línguas que aqui se territorializam.

\section{Povos, línguas e o atravessamento da cidade}

A discussão que desenvolvemos até aqui resultou numa cartografia de povos e línguas que, desde longa data, habitam o estado do Rio de Janeiro, movidos na ordem dos acontecimentos. As rotas migratórias têm sua insurgência dada a atualidade do acontecimento e, toda vez que buscamos a historicidade desses acontecimentos, nos encontramos no domínio da memória. Não se nega a importância política e histórica 
atribuída à cidade do Rio de Janeiro, e aqui se aloja um total maior ${ }^{22}$ daqueles que buscam por novos territórios. A imigração - causada por diferentes acontecimentos de ontem e hoje - acaba por resultar na (re)organização do território, metaforizado aqui na relação com o urbano. A cidade se configura por memórias transversas trazidas por povos e línguas que chegam de longe. Trazemos a foco, então, um pouco de reflexão sobre a cidade do Rio de Janeiro.

Pensar a relação cidade e sentido nos leva a buscar em Orlandi (2004) aspectos importantes na forma de como entender a cidade pelo viés do discurso. "Para nossa época, a cidade é uma realidade que se impõe com toda sua força. [...] Todas as determinações que definem um espaço, um sujeito, uma vida cruzam-se no espaço da cidade.” (idem, p.11)

Cruzam-se corpos diferentes e cruzam-se línguas, sem um significado imanente para muitos, mas com uma significância sonora ímpar. É paradoxal se ouvir nas ruas da cidade a língua do outro, mas que mesmo assim nos soam familiar. São línguas que se misturam aos ruídos da cidade, aos ruídos de nossa forma de falar, por isso mesmo emprestam à cidade a sua identidade. Faz parte do dia a dia do Rio de Janeiro, inúmeras expressões culturais diversas, funcionando como meio de integração - ou até de absorção - de línguas outras, que habitam o cotidiano da cidade, sempre aberta ao simbólico. E como se dá a (con)vivência com essas línguas? Pela hospitalidade:

\footnotetext{
““'Segundo Dauk (2006), Ulisses estabelece pela primeira vez os limites do mundo dos humanos e o critério do traçado deste limite é a hospitalidade. Esta ideia relaciona os humanos (eu diria os sujeitos) entre si por sobre as fronteiras étnicas e culturais." Mas o "estranho" nunca deixou de ser uma figura ambígua e a questão das fronteiras (espaços?) sempre se colocou. Pensar o multilinguismo em outra perspectiva que não a dessa ideologia da globalização pode ser uma maneira interessante de pensar as línguas como esse lugar de hospitalidade." (ORLANDI, 2012, p. 8)
}

A noção de hospitalidade - a partir de Orlandi - permite pensar numa "humanidade compartilhada [...]; que nossa relação com as línguas signifique em nossas

\footnotetext{
${ }^{22}$ A Região Sudeste, muito embora tenha sido o espaço onde a mobilidade foi a mais intensa, seguiu sua trajetória de diminuição no volume de imigrantes e emigrantes, situação que foi observada em todas as suas Unidades da Federação. Minas Gerais, apesar de ter permanecido como área de rotatividade migratória, apresentou saldo migratório ligeiramente negativo, enquanto o Rio de Janeiro permaneceu na categoria rotatividade migratória, com pequeno saldo migratório positivo e o estado de São Paulo aparece com declínio no saldo migratório, e mantendo-se como área de baixa absorção migratória (Censo IBGE 2010, apud SOUZA, 2018a).
} 
histórias”. (ORLANDI, 2014) As línguas originárias, as línguas de herança, as línguas de matriz africana, as línguas de santo, a linguagem dos LGBTs e as línguas dos que aqui se refugiam, todas trazem uma memória transversa. São línguas polissêmicas - não pelo caráter polissêmico de toda e qualquer língua - e sim pela materialidade sonora instituída no lastro de uma historicidade que se faz em território outro, na cidade do outro.

\section{Conclusão}

Nosso trabalho tomou como ponto de partida entender o universo linguístico sedimentado no estado fluminense. O Rio de Janeiro - berço do Império e capital da República por muitos anos - sempre se constituiu como um porto de chegada para os povos oriundos de todos os continentes. Desde o século XVIII, são muitas as línguas e falares em contato, numa troca linguística intermitente. Com a constituição de uma cartografia discursiva, fica evidente não só a pluralidade de línguas que têm sua fluência no Rio de Janeiro, como fica evidente também o Português como fio de entrelace de mais de um total de 160 línguas oficializadas em seus locais de origens (além das variedades dialetais dessas línguas), do fluxo de línguas autóctones de diferentes etnias, somando-se aí a língua de santo, o pajubá, o jeje e os falares iorubás - peças de herança dos povos escravizados.

Todo esse universo linguístico, certamente, afeta o modo de falar do português, bem como a língua portuguesa afeta a essas línguas, fazendo surgir línguas forjadas em território brasileiro - como o talian, o pomerano e outras.

Com a força do contato, a cidade do Rio de Janeiro, como atesta o censo do IBGE/2010, continua sendo o polo com algum crescimento de afluência de imigrantes, ao contrário de outros estados brasileiros. O que daí resulta é uma variedade de língua constituída por diferentes ocorrências fonéticas, fazendo com que o seu inventário fonético venha a ser um dos mais representativos em termos de variedades de sons da língua portuguesa em seu todo. Resultado, como se vê, da hospitalidade mútua entre as línguas.

Por esses aspectos, de ordem política e de ordem histórica, o dialeto carioca tem sido identificado como o dialeto padrão, desde o Congresso Nacional da Língua Cantada, organizado por Mário de Andrade em 1937 e o Congresso Nacional de Língua Falada no Teatro, realizado em 1956. Essa suposta supremacia vigora até os dias atuais. Enfim, em termos linguísticos, o modo de falar carioca refletiria o sistema fonológico da Língua Portuguesa em sua abrangência. Em termos históricos, esse modo de falar espelha os 
movimentos de uma história universal de desterritorialização, o que justifica a proposta de uma cartografia discursiva.

Em relação às políticas linguísticas, detectamos que até o momento não existem políticas públicas regulares que tratam dessa diversidade de línguas faladas no território do Rio de Janeiro e, por conta disso, uma série de problemas são instaurados, como por exemplo a questão do ensino de LIBRAS em território nacional. Obviamente, por ser interpretada pela mídia e pelo próprio governo como a segunda língua de comunicação oficial do país, seu ensino deveria se tornar obrigatório em todo território nacional, entretanto poucas são as ações políticas voltadas para a inserção da LIBRAS no ensino. No estado do Rio de Janeiro foi sancionada em 18/04/2019 a lei de número 8383/19 da autoria do Deputado Estadual Marcio Pacheco, que institui a criação das escolas da rede pública de educação bilíngue para surdos no âmbito do estado do Rio de Janeiro, porém até o presente momento de produção deste trabalho não tivemos informações de alguma escola específica em funcionamento.

Em relação à língua de imigrantes e de indígenas, não temos notícias de processo de cooficialização de algumas dessas línguas em território fluminense. Mas, por outro lado, há a cooficialização de LIBRAS no município do Rio de Janeiro.

No que diz respeito aos refugiados, observamos políticas linguísticas voltadas para o ensino de língua portuguesa. O governo do Estado do Rio de Janeiro, através do plano de acolhimento, estipulou, através da Secretaria Estadual de Assistência Social e Direitos Humanos, um curso de língua portuguesa para refugiados que funcionou como projeto piloto durante o ano de 2015 e 2016. Atualmente, o Programa de Atendimento a Refugiados e Solicitantes de Refúgio - Cáritas/RJ, em parceria com a Universidade do Estado do Rio de Janeiro, oferece o curso de língua portuguesa para estes indivíduos.

O trabalho no campo das políticas linguísticas não se encerra por aqui, quando buscamos responder a que línguas são faladas no Rio de Janeiro e o tratamento dado a elas em todo território do estado. Por outro lado, a hospitalidade que resulta na reorganização do urbano de cada cidade impõe um deslocamento contínuo da órbita da história. Eis aí um campo fértil de discussão.

\section{REFERÊNCIAS}

ARACIL, L. V. Sobre la situació minoritária. In: ARACIL, L. V. (org.). Dir la realitat. Barcelona: Edicions Països Catalans, 1983. p. 171-206. 
BAUMAN, Z. Amor líquido: sobre a fragilidade dos laços humanos. Rio de Janeiro: Jorge Zahar Ed., 2004.

CASTRO, Y. P. Das línguas africanas ao português brasileiro. Ano: 1983. Disponível $\mathrm{em}$ : https://repositorio.ufba.br (consulta: 30/12/2019 às 15:40)

CROCI, F. A imigração no Brasil. In: MELLO, H.et al (orgs). Os contatos linguísticos no Brasil. - Belo Horizonte: Ed UFMG, 2011

GADET, F.; PÊCHEUX, M. A língua inatingível: o discurso na história da linguística. Campinas, SP: Pontes, 2004 [1981].

HAMEL, R. E. La politica del linguaje y el conflicto interétnico: problemas de investigación sociolingüística. In: ORLANDI, Eni P. Política Lingüística na América Latina. p. 41-73 Campinas, SP: Pontes, 1988.

LESSER, Jeffrey. A negociação da identidade nacional: imigrantes, minorias e a luta pela etnicidade no Brasil, SP: Unesp, 2001.

MENEZES, L. M.. Jovens portugueses: histórias de trabalho, histórias de sucessos, histórias de fracassos. In: GOMES, A. de C.. (Org.). Histórias de imigrantes e de imigração. 1ed.Rio de Janeiro: Sete Letras, 2000, v. 1, p. 164-182.

MOURA, J. R. F. de. Da sombra às cores: análise discursiva do dicionário LGBTs e Aurélia. Tese (Doutorado) - Universidade Federal do Rio de Janeiro, Rio de Janeiro, 2018.

OLIVEIRA. G. M de.; ALTENHOFEN, C. V. $O$ in vitro $e$ o in vivo na política da diversidade linguística do Brasil: Inserção e exclusão do plurilinguismo na educação e na sociedade. In: Mello, H. et al. Os contatos linguísticos no Brasil. Belo Horizonte: Ed UFMG, 2011. Págs. 187-216

ORLANDI, E. P.; SOUZA, T. C. C. de. A língua imaginária e a língua fluída: dois métodos de trabalho com a linguagem. In: ORLANDI, E. (org). Política Linguística na América Latina. - Campinas, SP: Pontes Editores, 1988

ORLANDI, E. P. Espaços Linguísticos e seus desafios: convergências e divergências. Revista Rua no. 18, vol. 2, 2012

ORLANDI, E. P. Ciência da língua e política: Anotação ao pé das letras. Campinas, SP: Pontes Editores, 2014

ORLANDI, E. P. Cidade dos Sentidos. Campinas, SP: Pontes Editores, 2004.

PÊCHEUX, M. O discurso: estrutura ou acontecimento. Campinas, SP: Pontes, 1990.

PETTER, M. A influência das línguas africanas no português brasileiro. In: MELLO, Heliana et. all (org). Os contatos linguísticos no Brasil. Belo Horizonte: Ed. UFMG, 2011. Págs. 255-274

PONSO, L. C. Situação minoritária, população minorizada, língua menor: uma reflexão sobre a valoração do estatuto das línguas na situação de contato linguístico. Revista Gragoatá. Vol. 22. № 42, p. 184-207. jan-abr. 2017.

ROSA, R. P. S.; SOUZA, T. C. C. de. Política linguística, pluringuismo e consenso. Revista Interfaces. Vol. 10 n. 2, p. 118-128. 2019

ROSA, R.P.S. Plurilinguismo e política linguística em território fluminense: proposta de uma cartografia discursiva. Dissertação (Mestrado em Linguística) Faculdade de Letras. Universidade Federal do Rio de Janeiro, Rio de Janeiro, 2020. 96 f. 
SOUZA, T. C. C. de. A análise do não verbal e os usos da imagem nos meios de comunicação. RUA, Campinas, SP, v. 7, n. 1, p. 65-94, 2001 DOI: 10.20396/rua.v7i1.8640721.

SOUZA, T. C. C., ARAUJO, J. W. P. Práticas migratórias e movimentos na história: índios urbanos. Belo Horizonte, MG: XXV encontro Nacional da ANPOLL, 2010,

SOUZA, T. C. C. de. Língua nacional e materialidade discursiva: A influência do tupi. In: MELLO, Heliana et. al (org). Os contatos linguísticos no Brasil. Belo Horizonte: Ed. UFMG, 2011. Págs. 241-254.

SOUZA, T. C. C. de. Que línguas são faladas no Rio de Janeiro? Plurilinguismo e política de línguas. Santarém, PT: VI SIMELP, 2018a.

SOUZA, T. C. C. de. Refugiados e línguas de herança: plurilinguismo e política de línguas. Santarém, PT: VI SIMELP, $2018 \mathrm{~b}$.

SOUZA, T. C. C. de. Política linguística, política de línguas e línguas silenciadas. In. FIGUEIREDO, A. e REIS, L. (orgs). Estudos linguísticos nas línguas minoritarizadas. 2021 (no prelo)

Data de Recebimento: 29/03/2021

Data de Aprovação: 15/09/2021 


\section{Para citar essa obra:}

SOUZA, Tania Conceição Clemente de; ROSA, Rodrigo Pereira da Silva Plurilinguismo e cartografia discursiva do estado do Rio de Janeiro. In: RUA [online]. Volume 27, número 2 - p. 201-222 - e-ISSN 2179-9911 - novembro/2021. Consultada no Portal Labeurb - Revista do Laboratório de Estudos Urbanos do Núcleo de Desenvolvimento da Criatividade.

http://www.labeurb.unicamp.br/rua/

Capa: Mapa 5: Cartografia Discursiva.

Laboratório de Estudos Urbanos - LABEURB

Núcleo de Desenvolvimento da Criatividade - NUDECRI

Universidade Estadual de Campinas - UNICAMP

http://www.labeurb.unicamp.br/

Endereço:

LABEURB - LABORATÓRIO DE ESTUDOS URBANOS

UNICAMP/COCEN / NUDECRI

CAIXA POSTAL 6166

Campinas/SP - Brasil

CEP 13083-892

Fone/ Fax: (19) 3521-7900

Contato: http://www.labeurb.unicamp.br/contato 